\title{
SUCCESS AND FAILURE EFFECT ON SELF-EFFICACY AND PERFORMANCE: AN EXPERIMENTAL STUDY
}

\author{
Ronalds Cinks, Ivars Austers \\ University of Latvia, Latvia
}

\begin{abstract}
There is much correlational research singing praises for the validity and importance of selfefficacy. As well most people believe that optimistic view of one's capabilities would lead to higher performance. Some experimental research has cast doubt over the pervasive assumption that higher self-efficacy leads to higher performance. Specifically Control theory as opposed to the widespread Social Cognitive theory, argues that lower self-efficacy should result in higher performance. In this study we aimed to better understand the link between self-efficacy and performance, through both within and between individual comparison and to test whether a change in self-efficacy would lead to change in performance. To do this we carried out a single blind randomized between group experiment, where self-efficacy was manipulated with false feedback. The results showed that indeed self-efficacy shows a positive correlation with performance. Nevertheless, after the false feedback the positive and negative feedback groups did not differ in their performance on the second trial. In addition, the initial self-efficacy was significantly higher than any of the later self-efficacy measurements and higher than the actual performance on both occasions, but all the other self-efficacy measurements where not different from the actual performance scores. From the results it seems that self-efficacy is more of an ability to predict one's performance rather than a belief in one's capabilities. Since the randomization allowed to assume that both group's capabilities are the same, a decrease in self-efficacy did not affect performance. It could be that the overall positive correlation of self-efficacy and performance found in most correlational research is due to the confounding of actual capabilities. Actual capabilities being the cause of higher self-efficacy and higher performance. At least this seems to be true for simple fine motor tasks.
\end{abstract}

Keywords: expectations, false feedback, performance, self-efficacy, success/failure.

\section{Introduction}

Humans as opposed to most other living creatures have the ability to think about future (Roberts, 2002) and to take these thoughts into account when deciding on the best course of action (Baumeister et al., 2016). In 
general, when thinking about the future people are inclined to value optimistic thinking and prescribe optimistic thinking to others believing that it will increase performance (Armor et al., 2008; Tenney et al., 2015). Nevertheless, in the scientific literature there is no strict consensus on whether changes in psychological qualities increase future performance (Doron \& Gaudreau, 2014; Miller \& Weinberg, 1991; Vancouver \& Kendall, 2006; Vancouver et al., 2002; Vancouver et al., 2001; Woodman et al., 2010). This nonconclusive state of affairs is evident in different areas of human performance. For example, in sports after more than thirty years on the effects of psychological momentum the main conclusion has been that it as an artifact of performance not a cause (Avugos \& Bari-Eli, 2015), there have been even studies that show that increased self-efficacy can lead to detrimental behaviors, in workplace performance (Whyte \& Saks, 2007) in analytical tasks (Vancouver et al., 2002), group decision making (Whyte, 1998) and others.

One of the most researched aspects of psychological phenomena and its relationship to performance has been self-efficacy (Avugos \& Bari-Eli, 2015). Self-efficacy has been developed within the Social Cognitive theory (SCT; Bandrua, 1977), mainly suggesting that increasing one's self-efficacy (almost indefinitely) will have beneficial effects on performance. On the other side of the discussion are those who explain the effects of self-efficacy and performance through Control theory (Powers, 1978). From the later perspective higher self-efficacy would predict lower performance.

Bandura (1997) has written that: "People often fail to perform optimally even though they know full well what to do and possess the requisite skills to do it" (p. 37). He argues that self-efficacy is the missing link between actual skills and performance and that self-efficacy is an underlying factor of performance in any domain. Bandura (1977) introduced the concept of self-efficacy and defined it as an expectation of one's capabilities to carry out the behaviors needed for achieving an outcome. In theory self-efficacy affects the persons decision to engage in a behavior, how much effort they will exert and how long they will persist in a certain course of action. Importantly Bandura (1977) argues that: "The stronger the perceived self-efficacy, the more active the efforts." (p. 194).

A different approach to the effects of self-efficacy on performance can be found in the cybernetic or control system approach (Powers, 1978). From the perspective of Control theory (CT; Powers, 1978) higher self-efficacy would lead to less effort, since if one is so capable there is no need to exert extra effort to achieve one's goals (Vancouver et al., 2001). Another distinction is that within CT the perceived current performance or state and its cognitive perception influence the persons behavior. Accordingly, failure would signal to the person that the discrepancy between reality 
and the desired state has increased. This would create mental tension and hence more motivation to reduce it. Even Bandura (1977) himself noted that individuals set forth standards to which they compare their performance. Bandura (1977) theorized that, when the performance exceeds the standards put forth, the person feels a self-induced reward. These rewards in turn maintain the persons efforts to continue to meet those standards. In the case of failure, the person feels unsatisfied, which in turn motivates corrective changes in behavior. Thus, for Bandura (1977) failure and success leads to increase in performance, but for CT (Powers, 1978) failure leads to an increase, but success to a decrease in performance.

The general line of empirical research on self-efficacy shows that the tendency to hold optimistic or higher efficacy beliefs leads to better performance (e. g. Bandura, 1997; Stajkovic \& Luthans, 1998). Meta-analysis reveals that self-efficacy is more strongly related to performance than cognitive anxiety (Moritz et al., 2000; Woodman \& Hardy, 2003). Other research shows that increasing efficacy expectations has greater effect on performance than those of goal setting, feedback, or behavior modifications (Stajkovic \& Luthans, 1998). In athletic domains self-efficacy predicts positive effects on performance in such sports as diving, gymnastics, baseball, weightlifting, and wrestling (Feltz, 1982; Feltz \& Mugno, 1983; Fitzsimmons et al., 1991; George, 1994; Kane et al., 1996; McAuley, 1985). Furthermore, in a meta-analytic examination of 45 passive and experimental studies, Moritz et al. (2000) found self-efficacy to have a moderately positive relationship with performance $(r=.38)$. Therefore, most research continues to show that self-efficacy is an important predictor of performance (Feltz \& Magyar, 2006).

In the face of the vast amount of research on self-efficacies positive effect on performance there are still some who argue that the relationship actually should be reversed in line with CT (Vancouver \& Kendall, 2006; Vancouver et al., 2002). Majority of supporting evidence to the positive link of self-efficacy and performance comes from correlational research. Therefore, the counter argument goes that higher self-efficacy predicts higher performance, because the actual ability which could be the cause both for self-efficacy and the performance is not controlled for. It should be obvious then that people with higher ability should have as well higher self-efficacy, hence the positive correlation found in most research (Vancouver et al., 2001). Regarding that one of the most prominent sources of self-efficacy proposed in the original theory by Bandura (1997) is past performance, the previous argument seems even more plausible. Vancouver et al. (2017) argue that the person has inherent capacities which have brought about both past and present performance. If self-efficacy is derived from these performances, then it includes a large part of this capacity inherent to the person. 
There is some research that has tried to deal with the issue of directionality by trying to control for past performance. For example, Beattie et al. (2011) in their study about golf putting performance found that past performance explained almost half of the variation of self-efficacy, but self-efficacy had a negative effect on performance, the relationship was week and explained less than $5 \%$ of the variation in performance. Fitzsimmons et al. (1991) designed an experiment were experienced weightlifters were given false information about the weight they will have to lift. When thinking that the weight to be lifted was lighter than it was the participants were able to lift significantly heavier weights and in subsequent attempts the experienced weightlifters showed marked improvement. Nevertheless, the relationship with the improvement in the subsequent performance was almost perfectly predicted by past performance. The predictive value of self-efficacy on the other hand was much smaller and stopped showing any relation to the performance after several attempts. The authors conclude that with experienced athletes the past experience is almost the sole predictor of future performance and that self-efficacy has almost no added value. Further argument is made that self-efficacy might add value to those beginning athletes but serves little purpose to experienced ones (Feltz \& Mugno, 1983; McAuley, 1985). Other researchers have found similar effects of self-efficacy losing its predictive value once past performance is controlled (e. g. Mitchell et al., 1994; Feltz, 1982).

Another way of testing self-efficacy effects on performance has been through the effects of performance feedback, with the idea that it affects one's self-efficacy and thus should affect performance as well. Selfregulation theories and the idea of psychological momentum all posit that success breeds success, through increased psychological characteristics (e. g. self-efficacy) that enhance one's performance (Bandura, 1991; Latham \& Locke, 1991; Iso-Hola \& Dodson, 2014). Nevertheless, there are reasons to believe that the opposite is true, that a success leads to failure and failure leads to success. Gould et al. (1987), find that in the sport of pistol shooting higher confidence is related to lower shooting performance, Hardy et al. (2004) find the same pattern in golf, Vancouver et al. (2001) showed the same with analytical task, but going a step further by looking at the mechanism through which this decrease in performance occurs. They found that those who had higher self-efficacy where more likely to spend less time on deciding how to solve the problem, which in turn resulted in lower performance. The same pattern occurred in a follow up study, where the self-efficacy beliefs were artificially increased leading to a decreased performance (Vancouver et al., 2002), and in an academic context the students higher on self-efficacy spent less time preparing for examinations and subsequently getting a lower grade (Vancouver \& Kendall, 2006). 
The explanation for these types of results might be that high self-efficacy lead to overconfidence and therefore increase risk taking (Campbell et al., 2004) and/or complacency (Jones et al., 1993) and/or to lees focus and attention to the task (Mizruchi, 1991) all of which could thereafter decrease performance (Woodman et al., 2010). On the other hand, failure can increase motivation to prove one's abilities, and therefor try harder the next time and increase the probability of success (Mizruchi, 1991).

The present study aimed to further the understanding of the relationship between self-efficacy and performance, through experimentally manipulating self-efficacy beliefs. Both SCT (Bandura, 1977) and CT (Powers, 1978) predict that higher self-efficacy should be positively correlated with performance and taking into account that past performance is the main source of self-efficacy (Bandura, 1977) and that past performance should be dependent on actual capabilities (Vancouver et al., 2001) our first hypothesis is as follows:

H1: Self-efficacy will have a positive correlation with performance.

Nevertheless, CT (Powers, 1978) arguments that when two people have equal ability higher self-efficacy would lead to less effort if one were to engage in the particular task. It has been shown that overconfidence can lead to inattention, less effort and lower concentration (e. g. Vancouver \& Kendall, 2006; Campbell et al., 2004; Jones et al., 1993; Mizruchi, 1991). As well research on success/failure effects on performance have shown that success does not increase one's likelihood of future success (e. g. Avugos $\&$ Bar-eli, 2015), and that failure could actually lead to increased performance (e. g. Gould et al., 1987; Hardy et al., 2004; Vancouver et al., 2001). Therefore, the second hypothesis we propose is as follows:

H2: Negative feedback will cause a higher performance than a positive feedback on the subsequent performance.

\section{Method}

\section{Participants}

The participants were students who volunteered to participate on unpaid basis in the study. The final study sample comprised 80 participants, with almost equal gender proportions (41 males and 39 females), age range from 19 to 49 ( $M=25.60 ; S D=7.76)$. Participants were randomly assigned (using a random number list generator) to one of the two experimental groups ( $n=40$, false positive feedback; $n=40$, false negative feedback).

\section{Measurements and procedure}

A single blind experimental research design was used. To measure participants performance a wooden puck shooting board game was used. 
The game board is oval shaped $30 \mathrm{~cm}$ in length and $10 \mathrm{~cm}$ wide. At one long end a rubber band is set for the purpose of shooting the puck to the other end of the board. At the far end of the board, $13.5 \mathrm{~cm}$ from the rubber band, are depicted three lines (further called the point area), each stretches across the oval and is $2 \mathrm{~cm}$ wide. The aim of the game is by pulling and releasing the rubber band to shoot a little wooden puck $(2 \mathrm{~cm}$ in diameter) across the board so that the puck stops on to the point area. Participants in the beginning were instructed by the researcher about the purpose of the study (which was said to be about understanding how people acquire new skills) and the rules of the game. After the instructions the first self-efficacy measurement was made. The question was as follows - "if you now would shoot the puck 100 times, how many times you would manage to get the puck on to the point area?". The question was meant to measure participants efficacy expectations. After this question the participants were given the chance to practice shooting the puck for no more than two minutes. After the practice time was over the participants were asked for the second time the self-efficacy question. Then they were given 20 shots and said that the score will be counted. After this first performance measurement the participants received either positive or negative false feedback to which they were randomly assigned using a random number list generator. The negative feedback was "your score was lower than that of $50 \%$ of the previous participants" the positive feedback was identical except for one word that was changed - "your score was higher than that of $50 \%$ of the previous participants". The participants only received relative feedback and were not informed of their actual scores in absolute numbers. After that the participants gave their third self-efficacy measurement, after this the second trial of 20 shots, and finally the last, fourth self-efficacy measurement. All in all, there were 4 self-efficacy measurements and two performance measurements.

\section{Results}

Descriptive statistics of self-efficacy and performance measurements can be seen in Table 1. Manipulation check showed that the manipulation was successful. To test that indeed the groups will differ in their self-efficacy after the false feedback, Mann -Whitney test was used. Since third and fourth self-efficacy measurements were the only ones after the false feedback, these were the variables on which the two groups were compared. For the third self-efficacy measurement there were statistically significant differences, negative feedback group $(M d n=35.00)$ having lower self-efficacy than positive feedback group ( $M d n=42.50), U=593.50, z=-2.01$, $p=.045$. For the fourth self-efficacy measurement the negative feedback 
group $(M d n=37.50)$ and positive feedback group $(M d n=42.50)$ did not differ, $U=639.00, z=-1.56, n s$.

Table 1. Descriptive statistics for participants self-efficacy and performance and the results of Mann-Whitney group comparison tests

\begin{tabular}{|l|c|c|c|c|c|c|c|}
\hline & \multicolumn{2}{|c|}{$\begin{array}{c}\text { Negative } \\
\text { feedback group } \\
(\boldsymbol{n}=\mathbf{4 0 )}\end{array}$} & \multicolumn{2}{c|}{$\begin{array}{c}\text { Positive } \\
\text { feedback group } \\
(\boldsymbol{n}=\mathbf{4 0 )}\end{array}$} & \multicolumn{2}{c|}{$\begin{array}{c}\text { Overall } \\
(\boldsymbol{N}=\mathbf{8 0})\end{array}$} & \\
\hline & $\boldsymbol{M}$ & $\boldsymbol{S D}$ & $\boldsymbol{M}$ & $\boldsymbol{S D}$ & $\boldsymbol{M}$ & $\boldsymbol{S D}$ & $\boldsymbol{U}$ \\
\hline Self-efficacy Nr. 1 & 54.35 & 18.14 & 53.08 & 18.49 & 53.7 & 18.21 & 0.75 \\
\hline Self-efficacy Nr. 2 & 41.98 & 18.64 & 45.33 & 17.26 & 43.65 & 17.93 & 0.40 \\
\hline Performance Nr. 1 & 42.38 & 15.89 & 42.88 & 14.45 & 42.62 & 17.90 & 0.25 \\
\hline Self-efficacy Nr. 3 & 35.5 & 16.88 & 44.45 & 16.21 & 40.48 & 16.92 & 2.00 \\
\hline Performance Nr. 2 & 44.88 & 15.59 & 40.88 & 14.63 & 42.88 & 15.15 & 1.11 \\
\hline Self-efficacy Nr. 4 & 37.7 & 16.25 & 43.83 & 15.62 & 40.76 & 16.14 & 1.56 \\
\hline
\end{tabular}

$* p<.05$

To test the first hypothesis, that higher self-efficacy will have a positive correlation with performance Kendal Tau correlation was used (see Table 2). We can see that the only two variables that did not correlate are the first self-efficacy measurement and the first trial. All the other self-efficacy and performance measurements show significant positive correlations. Overall, the higher the self-efficacy on one measurement they will be higher on another measurement. The same for performance. The results indicating that higher self-efficacy right before the trials predicts higher performance within it (e. g. self-efficacy nr. 2 un trial nr. 1) are consistent with the first hypothesis.

Table 2. Kendal Tau correlations matrix for self-efficacy and performance $(N=80)$

\begin{tabular}{|l|c|c|c|c|c|}
\hline & $\mathbf{1}$ & $\mathbf{2}$ & $\mathbf{3}$ & $\mathbf{4}$ & $\mathbf{5}$ \\
\hline Self-efficacy Nr. 1 & - & & & & \\
\hline Self-efficacy Nr. 2 & $.47^{* *}$ & - & & & \\
\hline Performance Nr. 1 & .10 & $.27^{* *}$ & - & & \\
\hline Self-efficacy Nr. 3 & $.38^{* *}$ & $.71^{* *}$ & $.36^{* *}$ & - & \\
\hline Performance Nr. 2 & $.23^{* *}$ & $.23^{* *}$ & $.37^{* *}$ & $.23^{* *}$ & - \\
\hline Self-efficacy Nr. 4 & $.48^{* *}$ & $.54^{* *}$ & $.24^{* *}$ & $.61^{* *}$ & $.37^{* * *}$ \\
\hline
\end{tabular}

$* * p<.01$ 
In addition to correlations, we wanted to see whether the self-efficacy is overly optimistic. To do this we calculated Wilcoxon Signed rank test comparing both performance measurements against all the prior self-efficacy measurements in pairs. There was only one significant result. First efficacy measurement was significantly higher $(M d n=55.00)$ than both performance $\mathrm{nr} .1(M d n=40.00)$ and performance $\mathrm{nr} .2(M d n=40.00)$, $z=-4.07, p<.001$ and $z=-4.26, p<.001$, respectively.

To test the second and last hypothesis, that negative feedback group will show higher performance, as well Mann -Whitney test was used. The performance of negative feedback group $(M d n=45.00)$ and positive feedback group $(M d n=37.50)$ did not differ, $U=685.00, z=-1.11$, $n s$.

\section{Discussion}

In this research we tested two hypotheses. Our data supported the first hypothesis, that higher self-efficacy will predict higher performance. From the correlation analysis we were able to see that all the self-efficacy measurements prior to the performance measurements showed significant positive correlations, only the first self-efficacy measurement did not correlate with the first performance measurement. The positive correlation between self-efficacy and performance is in line with multitude of previous empirical research (e. g. Bandura, 1997; Stajkovic \& Luthans, 1998). From a theoretical point of view this result is coherent with both PC (Powers, 1978) and SCT (Bandura, 1977). The fact that the self-efficacy even before participants had a chance to try the game did not correlate with the first performance but did correlate with the second performance measurement is somewhat confusing and hard to explain. One explanation of the overall results could be as Vancouver et al. (2001) have hypothesized that even with unfamiliar tasks people have some insight into their capabilities, and thus they are able to predict to some degree how well they are going to fare. Of course, it could as well be that higher self-confidence leads to higher performance. Nevertheless, it seems more likely that individuals in this study did not possess equal skills at the beginning, therefore the correlation seems more in line to the former argument rather than the later.

As well we could see that the initial self-efficacy was the highest, it could even be described as unrealistically high since on the group level it exceeded the actual performance by 10 percent. All the other self-efficacy measurements once the participants had a chance to try out the game were significantly lower than the first one and could be described as realistic since they did not differ significantly from the actual performance. These results are in line with previous research that show that self-efficacy decreases when the feedback becomes nearer (e. g. Cinks \& Šaitere, 2018; 
Shepperd et al., 1996). It could as well be that when the participants had a chance to acquaint themselves with the task their prediction precision increased. As well the fact that the participants knew that they would get feedback right away and that a researcher is watching their performance could increase their accountability pressure and increase their motivation to be accurate in their predictions (Lerner \& Tetlock, 1999).

Finally, the second hypothesis was not supported by the current study. After the false feedback the performance of both groups did not differ. Nevertheless, we want to argue that this result is somewhat in more support to CT (Powers, 1978) than to SCT (Bandura, 1977). Since the self-efficacy right before the second trial were significantly different for both groups, with negative feedback group showing lower self-efficacy, both groups still did not differ in their performance. Thus, showing that a decrease in self-efficacy did not matter to the performance. Nevertheless, there could still be some other confounding aspects to the manipulation.

Regarding the limitations, a study by Seta and Hassan (1980) showed that the chance of exceeding expectations could be an important aspect of predicting the performance following success or failure. Thus it could be that in the current study after negative feedback people saw that they could prove themselves to the researcher on the second trial and therefore tried harder, but the positive feedback group had already proven themselves and there was less chance of exceeding the initial performance and thus tried less. It could be that this impression management process had interacted with self-efficacy beliefs and confounded the effects.

Some researchers have shown that more enduring traits such as self-esteem influence one's expectations (Sheppard et al., 1996), thus it could be that reaction towards the feedback and the subsequent performance were different for individuals with different self-esteem levels. However, for the present study we assume that this explanation was eliminated by the random assignment used to distribute the participants in experimental conditions.

Another point is that the false feedback manipulation worked, but nevertheless, the change in self-efficacy was short lived, because only right after the false feedback self-efficacy differed between the groups. Once the participants had another go at the game, the self-efficacy level again did not differ. Bandura (1977) in his theory of self-efficacy has argued that mastery experiences are more important than persuasive information. It could as well be that the decrease was due to negative emotions following the negative feedback. People tend to consider their affective state when trying to predict their performance (Clore et al., 1994). Since the third self-efficacy measurement was done right after the false feedback, the positive or negative affective state could have swayed the self-efficacy levels. 
The fourth measurement was made after the second trial, and the emotional state could have already passed. Finally, this could be as well due to accountability pressures diminishing, since the participants knew that there would be only two trials. Thus, on the fourth measurement participants were free to put forth forecasts that would not be tested (Carrol et al., 2006; Learner \& Tetlock, 1999).

Further, the task for measuring performance was a simple fine motor task which does not require much effort. Bandura (1977) has argued that self-efficacy mediates the capability performance link via engagement, perseverance, and effort. The task used in the current study did not require much of any of these traits. Therefore, it could be as well the case that the increase or decrease in self-efficacy does not matter for such a simple motor task hence the absence of an effect on performance. This tough should lay further credence for the assumption that self-efficacy as mainly measured in research is the ability to correctly predict one's performance and not a cause to increased performance (Vancouver et al., 2001).

As a final limitation it should be mentioned that the current study used a single blind experiment, where the researcher administering the experimental procedure was aware of the participants group assignment (positive or negative feedback). This could have biased the way the instruction, performance measurement and feedback were done.

For future research it would be important to eliminate the effects or false feedback on the persons chances of exceeding expectations in the future performance. One way to do this would be to use a similar $2 \times 2$ factorial design as in Seta and Hassan (1980) study, manipulating both feedback and the audience. Further, it would be beneficial in line with self-completion theory (Brunstein, 2000) to manipulate the meaningfulness of the task, to see whether that brings about a change within the false feedback performance dynamics. Finally, the tasks used to measure performance should be varied to see in which domains, if any, the relationship of self-efficacy and performance changes.

\section{Conclusions}

From the current research it seems more likely that self-efficacy judgements are more about the ability to predict one's performance rather than a belief in one's abilities, nevertheless the current design cannot fully disentangle this relationship. Overall people are overly optimistic when considering task performance with which one is unfamiliar, but that when the task is known and there are at least some accountability pressures the predictions become accurate. Both persuasive information and mastery experiences are important in influencing one's efficacy perceptions, but it seems 
that mastery experiences have a higher impact. At least in a simple motor task with no real-life consequences self-efficacy does not seem to increase or decrease performance in a causal matter.

\section{References}

Armor, D. A., Massey, C., \& Sackett, A. M. (2008). Prescribed optimism: Is it right to be wrong about the future?. Psychological Science, 19(4), 329-331.

Avugos, S., \& Bar-Eli, M. (2015). A Second Thought on the Success-Breeds-Success Model: Comment on. Review of General Psychology, 19(1), 106-111.

Bandura, A. (1977). Self-efficacy: toward a unifying theory of behavioral change. Psychological review, 84(2), 191.

Bandura, A. (1991). Social cognitive theory of self-regulation. Organizational behavior and human decision processes, 50(2), 248-287.

Bandura, A. (1997). Self-efficacy: The exercise of control. New York: Freeman.

Baumeister, R. F., Vohs, K. D., \& Oettingen, G. (2016). Pragmatic prospection: How and why people think about the future. Review of General Psychology, 20(1), 3-16.

Beattie, S., Lief, D., Adamoulas, M., \& Oliver, E. (2011). Investigating the possible negative effects of self-efficacy upon golf putting performance. Psychology of Sport and Exercise, 12(4), 434-441.

Brunstein, J. (2000). Motivation and performance following failure: The effortful pursuit of self-defining goals. Applied Psychology, 49(3), 340-356.

Campbell, W. K., Goodie, A. S., \& Foster, J. D. (2004). Narcissism, confidence, and risk attitude. Journal of behavioral decision making, 17(4), 297-311.

Carroll, P., Sweeny, K., \& Shepperd, J. A. (2006). Forsaking optimism. Review of General Psychology, 10, 56-73.

Cinks, R., \& Šaitere, S. (2018). Expectation Dynamics as Feedback Becomes Temporally Closer. Baltic Journal of Psychology, 19, 124-136

Clore, G. L., Schwarz, N., \& Conway, M. (1994). Affective causes and consequences of social information processing. In R. S. Wyer, Jr. \& T. K. Srull (Eds.), Handbook of social cognition: Basic processes; Applications (p. 323-417). Lawrence Erlbaum Associates, Inc.

Doron, J., \& Gaudreau, P. (2014). A point-by-point analysis of performance in a fencing match: Psychological processes associated with winning and losing streaks. Journal of Sport and Exercise Psychology, 36(1), 3-13.

Feltz, D. L. (1982). Path analysis of the causal elements in Bandura's theory of selfefficacy and an anxiety-based model of avoidance behavior. Journal of personality and Social Psychology, 42(4), 764.

Feltz, D. L., \& Magyar, T. M. (2006). Self-efficacy and adolescents in sport and physical activity. Self-efficacy beliefs of adolescents, 4, 161-179.

Feltz, D. L., \& Mugno, D. A. (1983). A replication of the path analysis of the causal elements in Bandura's theory of self-efficacy and the influence of autonomic perception. Journal of Sport and Exercise Psychology, 5(3), 263-277.

Fitzsimmons, P. A., Landers, D. M., Thomas, J. R., \& Van Der Mars, H. (1991). Does self-efficacy predict performance in experienced weightlifters?. Research Quarterly for Exercise and Sport, 62(4), 424-431. 
George, T. R. (1994). Self-confidence and baseball performance: A causal examination of self-efficacy theory. Journal of sport and exercise psychology, 16(4), 381-399.

Gould, D., Petlichkoff, L., Simons, J., \& Vevera, M. (1987). Relationship between Competitive State Anxiety Inventory-2 subscale scores and pistol shooting performance. Journal of Sport and Exercise Psychology, 9(1), 33-42.

Hardy, L., Woodman, T., \& Carrington, S. (2004). Is self-confidence a bias factor in higher-order catastrophe models? An exploratory analysis. Journal of Sport and Exercise Psychology, 26(3), 359-368.

Iso-Ahola, S., \& Dotson, C. (2015). Psychological Momentum-Not a Statistical but Psychological Phenomenon: Response to Commentary by Avugos and Bar-Eli (2015). Review of General Psychology, 19(1), 112-116.

Jones, G., Swain, A., \& Hardy, L. (1993). Intensity and direction dimensions of competitive state anxiety and relationships with performance. Journal of sports sciences, 11(6), 525-532.

Kane, T. D., Marks, M. A., Zaccaro, S. J., \& Blair, V. (1996). Self-efficacy, personal goals, and wrestlers' self-regulation. Journal of Sport and Exercise Psychology, 18(1), 36-48.

Latham, G. P., \& Locke, E. A. (1991). Self-regulation through goal setting. Organizational behavior and human decision processes, 50(2), 212-247.

Lerner, J. S., \& Tetlock, P. E. (1999). Accounting for the effects of accountability. Psychological bulletin, 125(2), 255.

McAuley, E. (1985). Modeling and self-efficacy: A test of Bandura's model. Journal of Sport and Exercise Psychology, 7(3), 283-295.

Miller, S., \& Weinberg, R. (1991). Perceptions of psychological momentum and their relationship to performance. The Sport Psychologist, 5(3), 211-222.

Mitchell, T. R., Hopper, H., Daniels, D., George-Falvy, J., \& James, L. R. (1994). Predicting self-efficacy and performance during skill acquisition. Journal of Applied Psychology, 79(4), 506.

Mizruchi, M. S. (1991). Urgency, motivation, and group performance: The effect of prior success on current success among professional basketball teams. Social Psychology Quarterly, 54(2), 181-189.

Moritz, S. E., Feltz, D. L., Fahrbach, K. R., \& Mack, D. E. (2000). The relation of selfefficacy measures to sport performance: A meta-analytic review. Research quarterly for exercise and sport, 71(3), 280-294.

Powers, W. T. (1978). Quantitative analysis of purposive systems: Some spadework at the foundations of scientific psychology. Psychological Review, 85(5), 417.

Roberts, W. A. (2002). Are animals stuck in time?. Psychological bulletin, 128(3), 473.

Seta, J. J., \& Hassan, R. K. (1980). Awareness of prior success or failure: A critical factor in task performance. Journal of Personality and Social Psychology, 39(1), 70.

Shepperd, J. A., Ouellette, J. A., \& Fernandez, J. K. (1996). Abandoning unrealistic optimism: Performance estimates and the temporal proximity of self-relevant feedback. Journal of Personality and Social Psychology, 70(4), 844.

Stajkovic, A. D., \& Luthans, F. (1998). Self-efficacy and work-related performance: A meta-analysis. Psychological bulletin, 124(2), 240.

Tenney, E. R., Logg, J. M., \& Moore, D. A. (2015). (Too) optimistic about optimism: The belief that optimism improves performance. Journal of personality and social psychology, 108(3), 377. 
Vancouver, J. B., Alicke, M., \& Halper, L. R. (2018). Self-efficacy. In D. L. Ferris, R. E. Johnson, \& C. Sedikides (Eds.), SIOP organizational frontiers series. The self at work: Fundamental theory and research (p. 15-39). Routledge/Taylor \& Francis Group.

Vancouver, J. B., \& Kendall, L. N. (2006). When self-efficacy negatively relates to motivation and performance in a learning context. Journal of applied psychology, 91(5), 1146.

Vancouver, J. B., Thompson, C. M., Tischner, E. C., \& Putka, D. J. (2002). Two studies examining the negative effect of self-efficacy on performance. Journal of applied psychology, 87(3), 506.

Vancouver, J. B., Thompson, C. M., \& Williams, A. A. (2001). The changing signs in the relationships among self-efficacy, personal goals, and performance. Journal of applied psychology, 86(4), 605.

Whyte, G. (1998). Recasting Janis's groupthink model: The key role of collective efficacy in decision fiascoes. Organizational Behavior and Human Decision Processes, 73(23), 185-209.

Whyte, G., \& Saks, A. M. (2007). The effects of self-efficacy on behavior in escalation situations. Human performance, 20(1), 23-42.

Woodman, T., Akehurst, S., Hardy, L., \& Beattie, S. (2010). Self-confidence and performance: A little self-doubt helps. Psychology of Sport and Exercise, 11(6), 467-470.

Woodman, T. I. M., \& Hardy, L. E. W. (2003). The relative impact of cognitive anxiety and self-confidence upon sport performance: A meta-analysis. Journal of sports sciences, 21(6), 443-457. 